\title{
The Laryngeal Anterior Commissure Stent for Anterior Glottic Synechiae
}

Vyas M.N. Prasad1,2, Raja Fakhoury¹, Diane Helou1, Mohammed Almohizea1

\section{Georges Lawson', Marc Remacle ${ }^{1,3}$}

1: Department of Otorhinolaryngology, Head and Neck Surgery, CHL UCL Yvoir, Belgium

2: National University Health System, Singapore 3: CHL Eich, Luxembourg

\section{NUHS}

\section{Introduction}

-Anterior glottic webs can be congenital or acquired. Congenital webs are rarer while acquired webs are usually related to trauma.

- The treatment of anterior glottic webs can be challenging. Several options have been successfully used - both open and closed.

- Currently, a greater focus on minimally invasive techniques has developed over the last two decades.

-The use of precision laser scanning systems, endolaryngeal instrumentation and trans-oral robotic techniques have been successfully described by several groups internationally.

\section{Aim}

We present our experience of a silastic stent (LACS- Laryngeal Anterior Commissure Stent) inserted endoscopically after laser division of these synechiae and aim to discuss the advantages of this minimally invasive treatment option in both children and adults.

\section{Methods}

This is a retrospective review of thirty- three cases in Belgium and Luxembourg using a self-made silastic stent initially and thereafter a ready made one. After $\mathrm{CO} 2$ laser division and application of mitomycin $\mathrm{C}$, the LACS was inserted endoscopically and secured to the skin of the neck.

Materials
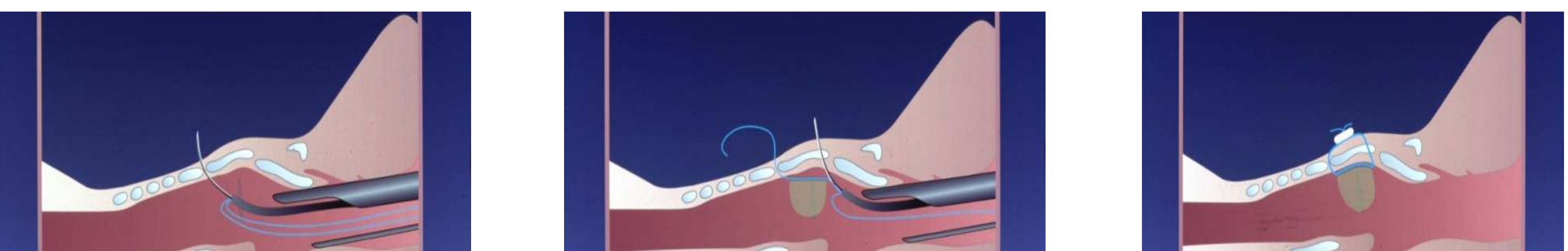

Above left to right: Stages of placement of silastic keel

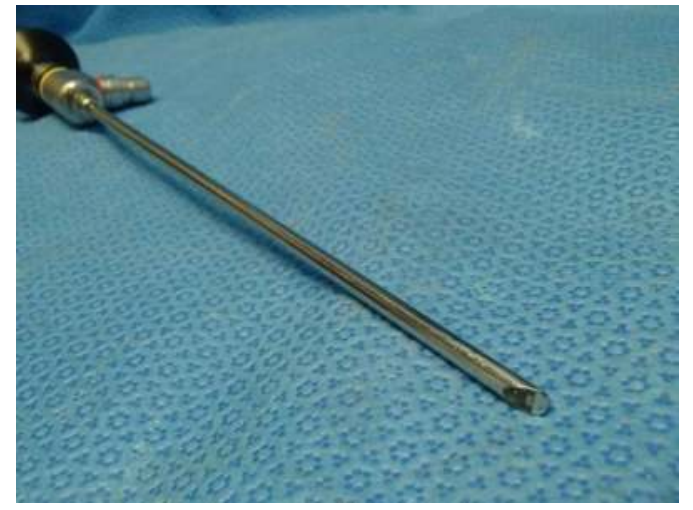

70 degree angled scope

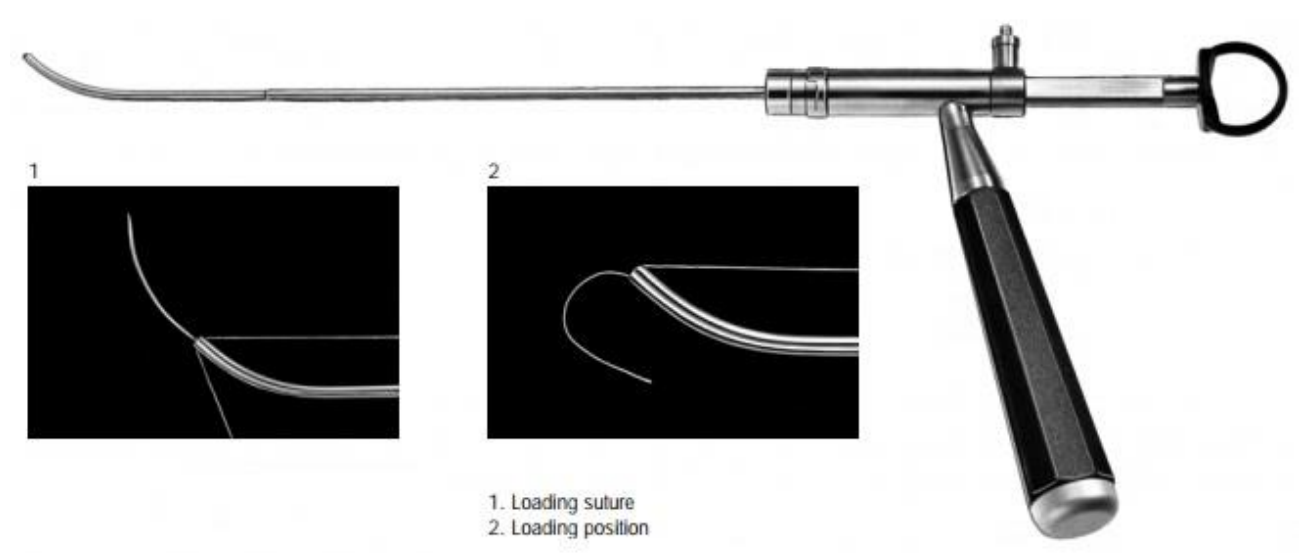

Lichtenberger needle holder

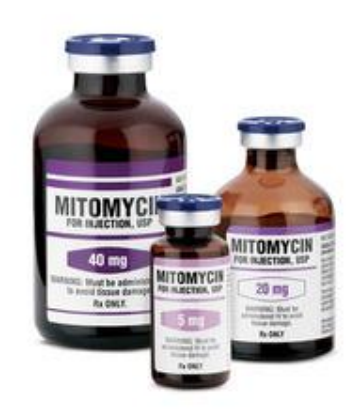

Mitomycin C
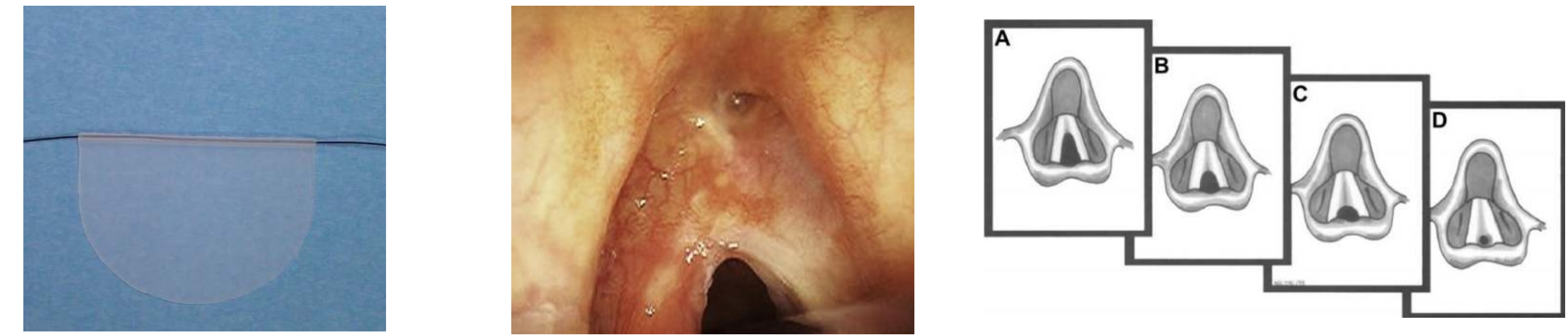

LACS with Prolene suture

Classification of Anterior Webs

\begin{tabular}{llll} 
& $\begin{array}{l}\text { Preoperative } \\
\text { values }\end{array}$ & $\begin{array}{l}\text { Postoperative } \\
\text { values }\end{array}$ & $p$ \\
\hline $\mathrm{G}$ & 2 & 1 & 0.035 \\
$\mathrm{R}$ & 2 & 1 & 0.083 \\
$\mathrm{VHI}$ & 54 & 46 & 0.263 \\
$\mathrm{MPT}(\mathrm{s})$ & 11.31 & 11.28 & 1 \\
$\mathrm{PQ}(\mathrm{m} / \mathrm{s})$ & 327 & 395 & 0.722 \\
$\mathrm{FR}(\mathrm{Hz})$ & 145 & 185 & 0.286 \\
$\mathrm{~F} 0(\mathrm{~Hz})$ & 211 & 222 & 0.944
\end{tabular}

\begin{tabular}{|l|c|c|}
\hline \multicolumn{1}{|c|}{ Cause } & N & $\%$ \\
\hline Transoral cordectomy & 15 & 46 \\
\hline Vocal fold microsurgery & 2 & 6 \\
\hline Larnngeal papillomatosis & 6 & 18 \\
\hline Long-term intubation & 3 & 9 \\
\hline Congenital web & 4 & 12 \\
\hline Idiopathic & 3 & 9 \\
\hline
\end{tabular}

\section{Results}

$1 \mathrm{RRP}$ patient required repeat stenting

\section{No AGW free}

1 expectorated stent

No aspiration

No damage to anterior commissure

Average time to stent removal : 21 days

No immediate or late Post Op complications

Mean FU 48.39 months $(3-87)$

No Tracheotomies required

Conclusion

Our results over the last fifteen years have shown that the LACS with mitomycin C can be used successfully in the management of anterior glottic webs in both adults and children with only one case requiring a second procedure and one expectoration of the stent
No recurrence, success $100 \%$

Pre \& Post op assessment:

Stroboscopy

$\mathrm{VHI}$

GRBAS

Aerodynamic and Acoustic measurements

Wilcoxon test computed, Significant if $p<0.05$ 